\title{
Two Novel Large ANKH Deletion Mutations in Sporadic Cases With Craniometaphyseal Dysplasia
}

Elaine H. Dutra

University of Connecticut School of Medicine and Dentistry

I-Ping Chen

University of Connecticut School of Medicine and Dentistry

Ernst J. Reichenberger

University of Connecticut School of Medicine and Dentistry

Follow this and additional works at: https://opencommons.uconn.edu/uchcres_articles Part of the Medicine and Health Sciences Commons

\section{Recommended Citation}

Dutra, Elaine H.; Chen, I-Ping; and Reichenberger, Ernst J., "Two Novel Large ANKH Deletion Mutations in Sporadic Cases With Craniometaphyseal Dysplasia" (2012). UCHC Articles - Research. 104.

https://opencommons.uconn.edu/uchcres_articles/104 


\title{
Two novel large $A N K H$ deletion mutations in sporadic cases with craniometaphyseal dysplasia
}

\author{
EH Dutra ${ }^{\mathrm{a}}$, I-P Chen ${ }^{\mathrm{b}}$, TL McGregor ${ }^{\mathrm{c}}$, JD Ranells ${ }^{\mathrm{d}}$, and EJ Reichenberger ${ }^{\mathrm{a}}$ \\ ${ }^{a}$ Department of Reconstructive Sciences, Center for Regenerative Medicine and Skeletal \\ Development, University of Connecticut Health Center, Farmington, CT, USA \\ ${ }^{b}$ Department of Oral Health and Diagnostic Sciences, School of Dental Medicine, University of \\ Connecticut Health Center, Farmington, CT, USA \\ 'Department of Pediatrics, Vanderbilt University School of Medicine and the Monroe Carell Jr. \\ Children's Hospital at Vanderbilt, Nashville, TN, USA \\ ${ }^{\mathrm{d} D e p a r t m e n t}$ of Pediatrics, University of South Florida College of Medicine, Tampa, FL, USA
}

\section{To the Editor:}

Craniometaphyseal dysplasia (CMD; OMIM \#123000) is a rare genetic disorder characterized by hyperostosis of craniofacial bones and metaphyseal flaring of long bones. Progressive bone thickening causes foraminal stenosis, which leads to the compression of cranial nerves and resultant facial palsy, hearing loss, and blindness. CMD is inherited as an autosomal dominant trait or occurs sporadically with apparent de novo mutations $(1,2)$. Here, we present two novel large deletions in exons 7 and 10 of $A N K H$ from two unrelated patients without the family history of CMD manifesting severe forms of the disorder.

Female patient 1 (Fig. 1a) had acute-onset left facial nerve palsy and subacute upper airway obstruction at 10 weeks of age. At 8 months, a temporal bone computed tomography (CT) revealed significant sclerosis of the skull base, which led to her diagnosis. At 9 months, she was diagnosed with hearing loss bilaterally necessitating hearing aids. Ophthalmologic evaluation at 10 months noted poor visual fixation and tracking in her left eye, left exotropia, and primary optic atrophy. She developed nystagmus at 12 months and subsequently had two episodes of orbital cellulitis. Progressive overgrowth of her inferior and middle turbinates prompted surgical resection to relieve obstruction, which was complicated by the marked density of the bone. By 17 months, she had the eruption of six normal teeth with hypertrophic appearing gums. With length consistently about the 20th percentile ( $-1 \mathrm{SD}$ ), her head circumference measured 1.62, 2.54, 3.07, and 3.87 SDs above the mean for age at $4,7,10$, and 17 months without hydrocephalus or narrowing of the foramen magnum. Alkaline phosphatase levels were persistently elevated, ranging from 427 to 1944 U/l (normal: 150-400). Other evaluations included normal total calcium levels, ionized calcium, which was normal at 1 week but elevated to $5.53 \mathrm{mg} / \mathrm{dl}$ (normal: $4.48-$ 5.28 ) at 8 months, and phosphorus, which was $2.7 \mathrm{mg} / \mathrm{dl}$ (normal 4.5-6.7) at 2 months but normal at 8 months.

(C) 2011 John Wiley \& Sons A/S

Correspondence: Dr. Ernst Reichenberger, PhD, Department of Reconstructive Sciences, University of Connecticut Health Center (UCHC), Center for Restorative Medicine and Skeletal Development, 263 Farmington Avenue, Farmington, CT 06030-3705, USA, Tel.: 860-679-2062, Fax: 860-679-2910, reichenberger@uchc.edu. 
Patient 2 (Fig. 1b) is a 5-year-old female who was evaluated for thickened calvarium and temporal bone with bony sclerosis of the internal auditory canals, cochleas, and semicircular canals, bilateral obliteration of mastoid air cells, and mixed bilateral hearing loss. Progressive hearing loss was diagnosed at 2 years of age. At 5 years, height was $115.3 \mathrm{~cm}$ (95th centile) and head circumference was $54.5 \mathrm{~cm}$ (3.4 SD above the mean). She has macrocephaly, tall broad forehead, hypertelorism, telecanthus, epiblepharon, paranasal bossing, excess vertical face height, prominent maxillary alveolar ridge, and borderline lowset posteriorly rotated ears. Dental examination showed normal primary dentition with normal occlusion. Neurologic examination showed mild left facial palsy. Alkaline phosphatase was minimally elevated at $324 \mathrm{U} / \mathrm{l}$ (normal for age 93-309). Serum calcium was normal, $9.4 \mathrm{mg} / \mathrm{dl}$ (normal 8.9-10.4), as was phosphorus, $4.3 \mathrm{mg} / \mathrm{dl}$ (normal 3.0-6.0).

Sequence analysis of $A N K H$ in patient 1 detected an extensive in-frame deletion of 18 nucleotides in exon 7 (c853-870del) affecting amino acids 285 to 290 (pV285-Y290del) (Gen- Bank \#BC014526) (Fig. 1c,d). Patient 2 had an extensive 12-base pair in-frame mutation in exon 10 of $A N K H$ (c1178-1189del) affecting amino acids 393 to 396 (pT393K396del) (Fig. 1e,f). Both deletions map to putative cytosolic regions of ANK. These mutations were not identified in the parents of the patients.

These novel 18 and 12 base pair in-frame deletions are the largest $A N K H$ mutations causing CMD identified to date, in addition to the recently identified complex mutation of two missense point mutations and a 12-bp deletion (3). All other previously identified mutations were inframe deletions of a single amino acid, an insertion of one amino acid due to a splicing defect, or amino acid substitutions due to point mutations $(1,2,4)$. Most of the mutations in $A N K H$ that we have identified in more than 40 families and sporadic cases previously reported single amino acid deletions p.Phe377del and p.Ser375del. In two cases, we found a previously identified alanine insertion (p.Pro380insAla) and in two other cases we detected point mutations (p.Cys331Arg, p.Trp292Arg). We noted variable expressivity in families and in sporadic cases with the same mutation.

CMD mutations in $A N K H$ affect exons 7-10, while mutations for chondrocalcinosis (CCAL2) involve exons 1, 2, and $12(5,6)$. In contrast to CMD, chondrocalcinosis is characterized by arthritic changes in joints due to the accumulation of calcium pyrophosphate dehydrate crystals, which form only in the presence of high pyrophosphate (PPi) levels. Interestingly, a novel mutation in exon 6 of $A N K H$ (Leu244Ser) has recently been associated with the first human progressive ankylosis phenotype with mental retardation, hearing loss, ankylosis, periarticular ligament ossification, enthesopathy, and dentinogenesis imperfecta (7). To date, the structural and functional impacts of the distinct mutations in ANKH remain speculative.

In summary, we report two novel in-frame deletions in patients with non-familial CMD affecting multiple amino acids in $A N K H$. Although both patients described here are severely affected, the size of the deletion or class of mutation does not appear to correlate with the severity of the disease.

\section{Acknowledgments}

We are indebted to the patients and their families for participating in this study. This study was supported by institutional funds and funding M01RR006192 (NIH) to the GCRC at UCHC and 5 T32 DE007302 (NIH) to E. H. D. Written consent for publication was obtained. 


\section{References}

1. Reichenberger E, Tiziani V, Watanabe S, et al. Autosomal dominant craniometaphyseal dysplasia is caused by mutations in the transmembrane protein ANK. Am J Hum Genet. 2001; 68:1321-1326. [PubMed: 11326338]

2. Nurnberg P, Thiele H, Chandler D, et al. Heterozygous mutations in ANKH, the human ortholog of the mouse progressive ankylosis gene, result in craniometaphyseal dysplasia. Nat Genet. 2001; 28:37-41. [PubMed: 11326272]

3. Zajac A, Baek SH, Salhab I, et al. Novel ANKH mutation in a patient with sporadic craniometaphyseal dysplasia. Am J Med Genet A. 2010; 152A:770-776. [PubMed: 20186813]

4. Kornak U, Brancati F, Le Merrer M, et al. Three novel mutations in the ANK membrane protein cause craniometaphyseal dysplasia with variable conductive hearing loss. Am J Med Genet A. 2010; 152A:870-874. [PubMed: 20358596]

5. Pendleton A, Johnson MD, Hughes A, et al. Mutations in ANKH cause chondrocalcinosis. Am J Hum Genet. 2002; 71:933-940. [PubMed: 12297987]

6. Williams CJ, Zhang Y, Timms A, et al. Autosomal dominant familial calcium pyrophosphate dihydrate deposition disease is caused by mutation in the transmembrane protein ANKH. Am J Hum Genet. 2002; 71:985-991. [PubMed: 12297989]

7. Morava E, Kuhnisch J, Drijvers JM, et al. Autosomal recessive mental retardation, deafness, ankylosis, and mild hypophosphatemia associated with a novel ANKH mutation in a consanguineous family. J Clin Endocrinol Metab. 2011; 96:E189-E198. [PubMed: 20943778] 
(a)

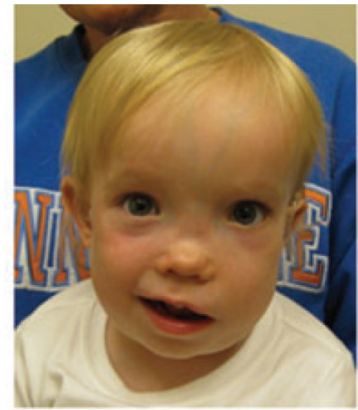

(b)

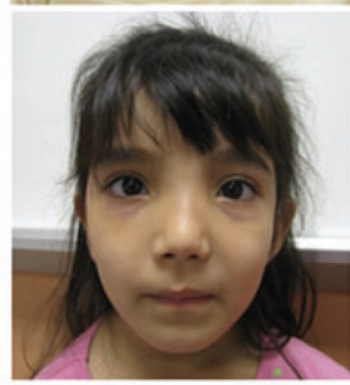

(c) Forward

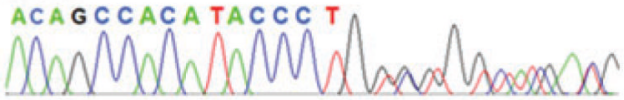

Reverse

T TCCG TCAACCAGCC

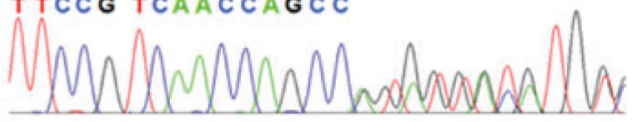

(d)

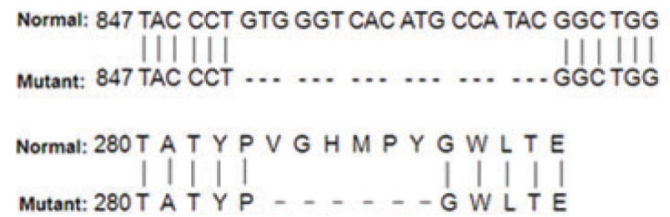

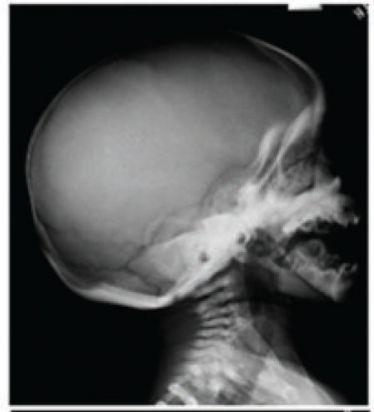
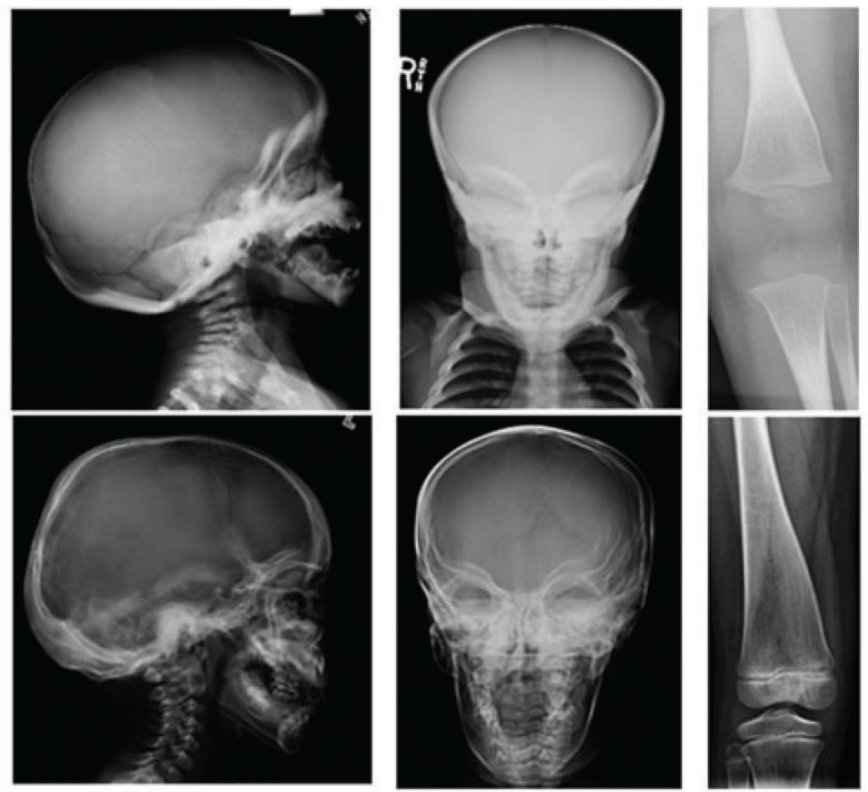

(e) Forward

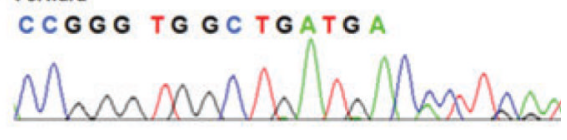

\section{Reverse}

GGGCAAGGACGAAGG

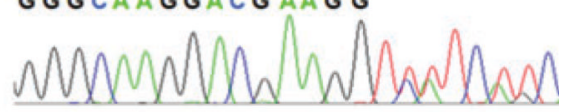

(f) Normal: 1172 TGA TGA CAC TGA AGA AAA CCT TCG

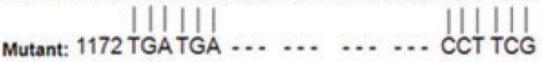

Normal: 388 T G W L M T L K K T F V L A l $\mid$ i l |||| $\mid$ Mutant: 388 T G W L M - - - T F V L A

(g)

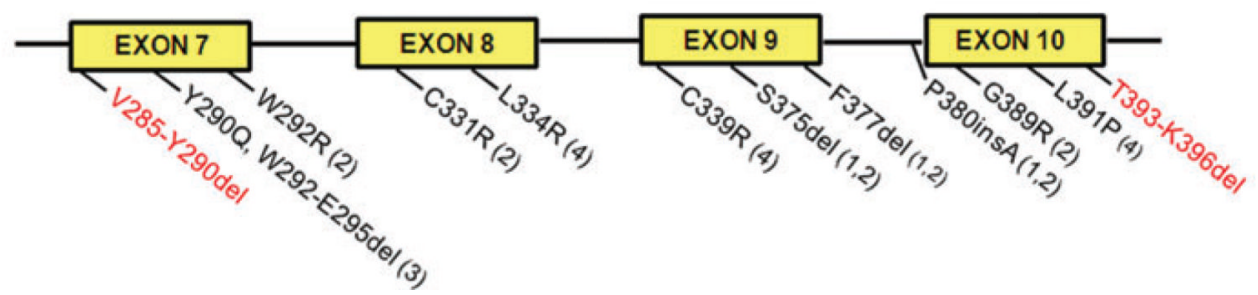

Fig. 1.

(a) Craniometaphyseal dysplasia (CMD) patient 1 presents with frontal bossing, macrocephaly, and a left facial palsy. Her distal femur and proximal tibia show typical metaphyseal flaring. (b) CMD patient 2 presents with characteristic facies, hyperostotic cranial bones, and flaring of long bone metaphyses. (c) Electropherogram showing a heterozygous deletion in exon 7 of the $A N K H$ genomic DNA from CMD patient 1 . (d) Sequence comparison to wild type sequence shows an $18 \mathrm{bp} / 6$ aa in-frame deletion. (e) Electropherogram showing a deletion in exon 10 of the $A N K H$ genomic DNA from CMD patient 2. (f) Sequence comparison to wild type sequence shows a $12 \mathrm{bp} / 4$ aa in-frame 
deletion. (g) Mutations for CMD located in exons 7, 8, 9, and 10 of $A N K H$. New mutations indicated in red. 